\title{
Bilateral cataract extraction in one session: report on five years' experience*
}

\author{
NISSIM JOSEPH AND ROBERT DAVID \\ From the Department of Ophthalmology, University of the Witwatersrand, Johannesburg, South Africa
}

SUMMARY Six hundred and seventy-six patients had both their cataracts removed in one operating session because of the rural and economic conditions of Malawi. These operations were performed over a period of 5 years. The final visual results were satisfactory and the number of complications acceptable in relation to the environmental conditions and medical facilities available. However, the incidence of infection is higher than would be acceptable in a sophisticated medical environment. Three eyes were lost owing to infection, but fortunately in all 3 cases the fellow eye was not affected. Furthermore, broken capsule and vitreous loss occurred more frequently than expected in a sophisticated facility in the eye first operated on. This allowed measures to be taken by the surgeon in many cases to prevent these complications from recurring in the second eye.

With the increase in safety of cataract surgery and the expansion of ophthalmological services to remote places of the world there have been a few encouraging reports in the last 20 years which advocate surgery for bilateral cataracts-under certain circumstances-in one operating session (Chan and De La Paz, 1952; Manschot, 1959; Morax and Pivoteau, 1967; Lugossy, 1968; Jardine, 1972; Suchting, 1973). Simultaneous bilateral cataract extraction is still rather unpopular among experienced ophthalmologists. This is mainly due to fear of postoperative infection, which, should it occur, is still considered to present a danger to both operated eyes. This fear seems to be deeply rooted, since Blaskovicz in the 1930s sharply criticised Elshnig for performing such an 'erratic' procedure (Manschot, 1959). This report presents a large series of simultaneous bilateral cataract extractions, enforced by the circumstances of the ophthalmological services in Malawi, with a constant shortage of hospital beds and long distances to the only eye department where surgery for cataract is available.

\section{Material and methods}

In the 5 years between 1 January 1970 and 31 December 1974, 676 patients (1352 eyes) with

*This report is based on the experience of the authors at the Queen Elizabeth Central Hospital in Blantyre, Malawi, while seconded from the Hadassah Hospital, Jerusalem, in the years 1970-71 (R.D.) and 1972-74 (N.J.)

Address for reprints: Dr Robert David, Department of Ophthalmology, Medical School, Hospital Street, Johannesburg 2001, South Africa bilateral cataracts were operated on at the Queen Elizabeth Central Hospital in Blantyre, and both cataracts were removed at one operating session. General anaesthesia was the rule except in those cases in which the patient was considered an anaesthetic hazard. There was no rescrubbing between the operation on the 2 eyes, and only the innermost drape was replaced for the second eye. The operation instruments were not resterilised after the first operation.

The surgical technique employed was as follows: After a conjunctival flap (usually limbal based) was raised, a limbal groove was performed with or without preplaced sutures. After anterior chamber had been opened 1 or 2 peripheral iridectomies were performed. Chymotrypsin was used in patients under 60 years of age. Unfortunately, this drug was frequently unavailable. The lens was delivered with Arruga intracapsular forceps or erysiphake for the first 2 years and mainly with the cryoceps afterwards. Intracapsular extraction was attempted in all cases, and if the capsule ruptured every effort was made to evacuate the remnants, including the posterior capsule. In cases where the anterior vitreous face was broken an anterior vitrectomy was performed, using Weck-cell and iris scissors. Sutures used were either 7.0 or 8.0 virgin silk, usually a total of 8 or 9 . The conjunctiva was resutured.

The average operating time for the 2 eyes was 60 70 minutes. An operating microscope was used only during the last year.

Preoperative conjunctival swabs were not routinely taken owing to shortage of laboratory facilities. In the first 2 years all patients received systemic anti- 
biotics for 5 postoperative days, but this was stopped in 1972. The type of antibiotic used depended on availability in the pharmacy and was mainly synthetic penicillin.

Postoperative care included uncovering the more quiet-appearing eye on the first postoperative day and ambulation of patients on the 3rd or 4th day. The patients were discharged 8-12 days after the operation, the time depending on the distance to their villages.

Topical treatment included cycloplegic and chloramphenicol drops and, when necessary, steroids. The medical stores supplied standard spherical +8.00 to +14.00 dioptre sphere glasses free of charge. The glasses, however, were actually given to the patient only on their second or third follow-up visit, usually 2-3 months after surgery. This provided us with a reasonably good follow-up in practically all cases.

There were 494 males and 182 females, a ratio of $2 \cdot 7: 1$. The majority of patients $(84.9 \%)$ were under 70 years of age. The age distribution is seen in Table 1.

\section{Results}

VISUAL RESULTS

Four hundred and ninety-four patients (988 eyes) returned for follow-up at least 2 months after surgery. The visual acuity with correction is seen in Table 2. Eighty-six eyes did not regain useful vision, and the ocular pathology in these eyes is seen in Table 3.

\section{OPERATIVE COMPLICATIONS}

In a total of 130 eyes $(9.6 \%)$ the lens capsule broke during delivery, but only in 28 eyes were both eyes of the same patient involved (14 patients). In 67 patients it occurred in the first eye operated on and in 35 in the second eye operated on (Table 4). Loss of vitreous requiring anterior vitrectomy occurred in 90 cataract extractions $(6.6 \%)$. In 43 patients this occurred in the first eye only and in 25 cases in the second eye only. Eleven patients suffered vitreous loss in both their eyes (Table 4). Expulsive haemorrhage was not seen in any of the operated eyes.

\section{POSTOPERATIVE COMPLICATIONS}

Three eyes in 3 different patients had a postoperative endophthalmitis: 1 had bilateral vitreous loss at the time of the surgery, and the eye first operated on became infected 48 hours after the extraction. The second patient had vitreous loss in the left eye, the first eye operated on, and an uncomplicated extraction on the right. The left eye only developed endophthalmitis. The last patient had uncomplicated bilateral surgery, and $\mathbf{4 8}$ hours later the right
Table 1 Age distribution of bilateral cataract patients

\begin{tabular}{lr}
\hline Years & No. \\
\hline \multirow{n}{n}{$\leqslant 59$} & 271 \\
$60-69$ & 303 \\
$70-79$ & 80 \\
$\geqslant 80$ & 22 \\
Total & 676 \\
\hline
\end{tabular}

Table 2 Visual results in 494 patients (988 eyes)

\begin{tabular}{lr}
\hline Visual acuity & No. \\
\hline$<6 / 60$ & 86 \\
$6 / 36-6 / 60$ & 194 \\
$6 / 12-6 / 24$ & 347 \\
$\geqslant 6 / 12$ & 361 \\
Total & 988 \\
\hline
\end{tabular}

Table 3 Ocular pathology in 86 eyes with $<6 / 60$ vision

\begin{tabular}{llll}
\hline Finding & $\begin{array}{l}\text { Uncomplicated } \\
\text { surgery }\end{array}$ & $\begin{array}{l}\text { Vitreous loss } \\
\text { during } \\
\text { extraction }\end{array}$ & Total \\
\hline Pre-existing corneal opacity & 19 & - & 19 \\
Corneal oedema & 8 & 9 & 17 \\
Glaucomatous optic atrophy & 14 & 1 & 15 \\
Primary optic atrophy & 8 & - & 8 \\
$\begin{array}{l}\text { Vitreous haemorrhage } \\
\text { (diabetes) }\end{array}$ & 4 & 3 & 7 \\
$\begin{array}{l}\text { Vitreous haemorrhage } \\
\text { (non-diabetic) }\end{array}$ & 3 & 1 & 4 \\
Retinal degeneration & 6 & - & 6 \\
Macular hole & 3 & - & 3 \\
Amblyopia & 5 & - & 5 \\
Retinal detachment & - & 2 & 2 \\
Total & 70 & 16 & 86 \\
\hline
\end{tabular}

Table 4 Operative complications

\begin{tabular}{lllll}
\hline Complication & $\begin{array}{l}\text { Patient } \\
\text { 1st eye only } \\
(\%)\end{array}$ & $\begin{array}{l}\text { Patient } \\
\text { 2nd eye only } \\
(\%)\end{array}$ & $\begin{array}{l}\text { Patient } \\
\text { both (\%) }\end{array}$ & $\begin{array}{l}\text { Total } \\
\text { eyes (\%) }\end{array}$ \\
\hline Ruptured capsule & $67(4 \cdot 9)$ & $35(2 \cdot 5)$ & $14(2 \cdot 0)$ & $130(9 \cdot 6)$ \\
Broken vitreous & $43(3 \cdot 1)$ & $25(1 \cdot 8)$ & $11(0 \cdot 8)$ & $90(6 \cdot 6)$ \\
\hline
\end{tabular}


Table 5 Visual results in 56 eyes after vitrectomy

\begin{tabular}{ll}
\hline Visual acuity & Eyes \\
\hline$<6 / 60$ & 16 \\
$6 / 36-6 / 60$ & 16 \\
$6 / 24-6 / 12$ & 14 \\
$\geq 6 / 12$ & 10 \\
Total & 56 \\
\hline
\end{tabular}

eye (first operated on) developed endophthalmitis.

Of the 90 eyes with anterior vitrectomy 56 were seen 2 months or more after surgery, and their visual results are shown in Table 5.

\section{Discussion}

We did bilateral cataract operations in a single session to meet the problems of a young and developing African country. It was necessary to shorten the patient's time in hospital and ensure a quick turnover to overcome the permanent shortage of beds. Retrospectively, however, there are certain advantages, some of which have already been emphasised by authors advocating this method.

We prefer general to local anaesthesia for cataract surgery, and removing both cataracts in one session saves the patient an additional general anaesthetic.

The fact that either capsule rupture or vitreous loss occurred more frequently in the first eye operated on indicates that these complications were subsequently avoided by some special precaution or modification adopted at the operation on the second eye. A minor detail which triggered the complication in the first eye alerted the surgeon, who could take suitable precautions in the operation immediately following on the second eye. Such a minor detail can be easily overlooked in the operating notes at the time the second eye is subjected to surgery, if this is done at a later date. This is especially true when the second operation is performed by another surgeon.

In the 585 simultaneous cataract extractions reported by Jardine (1972) there were 3 intraocular infections, each affecting one eye of 3 patients. The 3 cases of endophthalmitis in our series also occurred in one eye of 3 patients, while the fellow eye of all these patients remained unaffected.
Anterior vitrectomy is believed to predispose to infection, and this was the case in 2 of our 3 cases. This, however, does not incriminate bilateral surgery, because in 11 patients with bilateral vitreous loss only 1 eye of 1 patient developed an infection.

The relatively high incidence of operative complications such as ruptured capsules and vitreous loss in this series is cause for some concern and comment. It can, at least partially, be attributed to (1) the types of cataract with which our patients presented-frequently hypermature, intumescent, and not uncommonly subluxated; (2) use of the cryoextractor only in the last 3 years and then only on selected cases; and (3) the shortage of chymotrypsin, which was unavailable for various periods.

However, this still leaves unexplained a relatively high incidence $(0.22 \%)$ of postoperative endophthalmitis. Three eyes out of 1352 operations were lost, fortunately not involving 2 eyes from a single patient. This incidence of endophthalmitis and the possibility that both eyes of one patient could be affected remains the strongest argument against simultaneous bilateral cataract extraction at one surgical session unless there are very cogent social and economic reasons, such as exist in Malawi and many other developing countries.

The ultimate visual result, however, suggests that operating on bilateral cataracts at one session can be an acceptable procedure in certain environmental communities where socioeconomic conditions make it difficult for patients to be readmitted and where medical facilities have to be used sparingly. The patient is saved from double preoperative stress, two general anaesthetics, and time in hospital is shortened. Administrative authorities welcome the economy in operating time, anaesthetic time, hospital beds, and operating theatre expenses.

\section{References}

Chan, J. O., and De La Paz, P. (1952). Journal of the Philippine Medical Association, 28, 700.

Jardine, P. (1972). Transactions of the Ophthalmological Societies of the United Kingdom, 90, 719.

Lugossy, G. (1968). Annales d'Oculistique, 202, 969.

Manschot, W. A. (1959). Ophthalmologica, 137, 428.

Morax, P. V., and Pivoteau, B. (1967). Annales d'Oculistique, $200,392$.

Suchting, P. (1973). Klinische Monatsblätter für Augenheilkunde, 163, 92. 